\title{
Differential Exosomic Proteomic Patterns and Their Influence in Resveratrol Sensitivities of Glioblastoma Cells
}

\author{
Jun-Hua Nie ${ }^{1}$, Hong $\mathrm{Li}^{2}{ }^{2}$ Mo-Li Wu ${ }^{2}$, Xiao-Min Lin ${ }^{1} \mathbb{D}$, Le Xiong ${ }^{1}$ and Jia Liu ${ }^{1,2, *}$ \\ 1 School of Medicine, South China University of Technology (SCUT), Guangzhou 510000, China; \\ mcnie@mail.scut.edu.cn (J.-H.N.); mcsmall@mail.scut.edu.cn (X.-M.L.); \\ 201710106932@mail.scut.edu.cn (L.X.) \\ 2 Department of Cell Biology, College of Basic Medical Sciences, Dalian Medical University, Dalian 116044, \\ China; lihongmcn@dlmedu.edu.cn (H.L.); moliwusx@sina.com (M.-L.W.) \\ * Correspondence: mcliujia@scut.edu.cn or jialiudl@aliyun.com; Tel.: +86-203-938-0270
}

Received: 10 December 2018; Accepted: 2 January 2019; Published: 7 January 2019

\begin{abstract}
Glioblastoma multiforme (GBM) is the commonest primary brain malignancy with extremely poor prognosis. Resveratrol posseses anti-cancer effects, while GBM cells respond differently to it due to certain unknown reason(s). Because the tumor-derived exosomes are supposed to influence chemosensitivity, the exosomic proteins released from resveratrol-sensitive U251 and resveratrol-resistant glioblastoma LN428 cells are profiled before (N/Exo) and after drug treatment (Res/Exo) by label-free liquid chromatography-mass spectrometry (LC-MS). The therapeutic implications of the proteomic findings are estimated by gene ontology enrichment analysis (GO) and the Kyoto Encyclopedia of Genes and Genomes (KEGG)-based bioinformatic analyses and further elucidated by exosome co-incubating. The results reveal that U251/N/Exo but not U251/Res/Exo enhances resveratrol sensitivity of resveratrol-resistant LN428 cells. The resveratrol sensitive properties of U251 cells are not altered by either LN428/N/Exo or LN428/Res/Exo. U251/N/Exo contains higher levels of chromatin silencing and epidermis development proteins, while U251/Res/Exo has more oxygen transport and G protein-coupled receptor. Both of LN428/N/Exo and LN428/Res/Exo are rich in the proteins related with nucleosome assembly, microtubule-based process and chromatin silencing. In conclusion, U251/N/Exo sensitizes LN428 cells to resveratrol via delivering drug sensitizing signals, suggesting the presence of additional factor(s) that may determine the resveratrol sensitivities of glioblastoma cells.
\end{abstract}

Keywords: glioblastoma cells; resveratrol; exosome; proteomics; drug sensitivity

\section{Introduction}

Glioblastoma multiform (GBM) is the most common primary brain malignancy with annual incidence of about 3/100,000 [1]. The standard care for GBM is maximum feasible surgical resection followed by temozolomide-based chemotherapy [2]. However, this combined therapy merely gains about 15 months of median overall survival time because of high recurrent rates and frequent radioand chemo-resistance [3]. Moreover, the anti-glioblastoma drugs currently used cause severe toxic effects [4] and consequently reduce the quality of life of GBM patients [5]. It would therefore be of therapeutic value to explore alternative approaches for the better treatment of this lethal malignancy.

Resveratrol (trans-3,5,4'-trihydroxystibene, $\mathrm{C}_{14} \mathrm{H}_{12} \mathrm{O}_{3}$ ), the natural plant-derived compound, posses multiple anticancer activities including sensitization of radiation and chemotherapy by promoting the differentiation of cancer cells [6]. This lipophilic compound is able to cross the blood-brain barrier through simple diffusion and exerts anti-cancer effects in the brain [7]. Moreover, 
resveratrol exhibits little adverse effect on normal brain cells in vitro [8] and in vivo [9], indicating its safety for practical application. So far, resveratrol has not yet been clinically used because of its low in vivo bioavailability when administered systemically [10]. This therapeutic dilemma can be largely overcome via organ-targeted drug delivery [11]. For instance, lumbar puncture-delivered resveratrol efficiently suppresses rat orthotopic GBM growth [12], especially when it is applied post-operatively [13]. The above results suggest resveratrol as a potential agent against human GBMs.

It has been found that human GBM cell lines respond differently to resveratrol [14]. For instance, the human U251 cell line is highly sensitive to resveratrol in terms of distinct growth arrest and extensive apoptosis, while the LN428 cell line shows little response under the same experimental conditions [15]. These findings suggest the necessity to investigate the underlying reason(s) leading to the distinct response of GBM cells to resveratrol for personalized anti-GBM therapy. It has been supposed that the exosomes released from drug-resistance cancer cells can increase the drug-tolerance of the receptor cells including GBM cells [16]. However, no datum has been so far available concerning (1) the impact of exosomes from drug-sensitive cells in drug sensitivity and (2) the relevance of exosomic patterns with resveratrol sensitivities of GBM cells. The current study thus aims to address the above issues by profiling exosomic proteins of U251 and LN428 cells before and after resveratrol treatment and bi-directionally analyze their influence in resveratrol sensitivity.

\section{Results}

\subsection{Distinct Response of $U 251$ and LN428 to Resveratrol}

The results of hematoxylin-eosin (H/E) morphological staining demonstrate that U251 cells showed growth arrest and extensive cell death after $100 \mu \mathrm{M}$ resveratrol treatment for $48 \mathrm{~h}$, while no distinct cell death was found in the LN428 cell population (Figure 1A). MTT cell proliferation assay (Figure $1 \mathrm{~B})$ revealed that $\mathrm{OD}$ value $(0.310 \pm 0.020$, cell viability $=50.1 \%)$ of resveratrol-treated U251 cells was significantly reduced in comparison with that $(0.618 \pm 0.103, p<0.01)$ of the untreated counterpart; the mean OD values $(0.743 \pm 0.047)$ of resveratrol-treated LN428 cells and untreated cells $(0.722 \pm 0.185, p=0.375)$ have no significant different. These results indicate that $\mathrm{U} 251$ rather than LN428 cells were sensitive to resveratrol.

A

U251
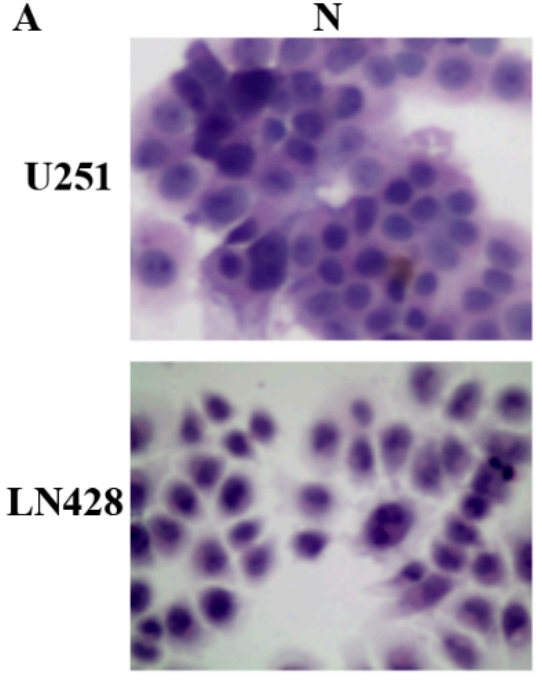

$\mathbf{R}$
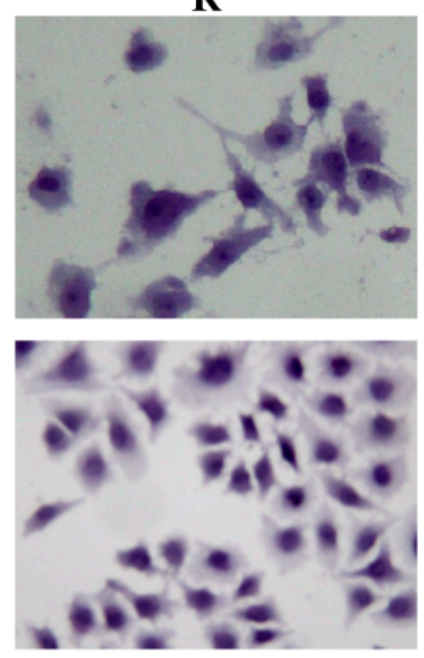

Figure 1. Cont. 
B

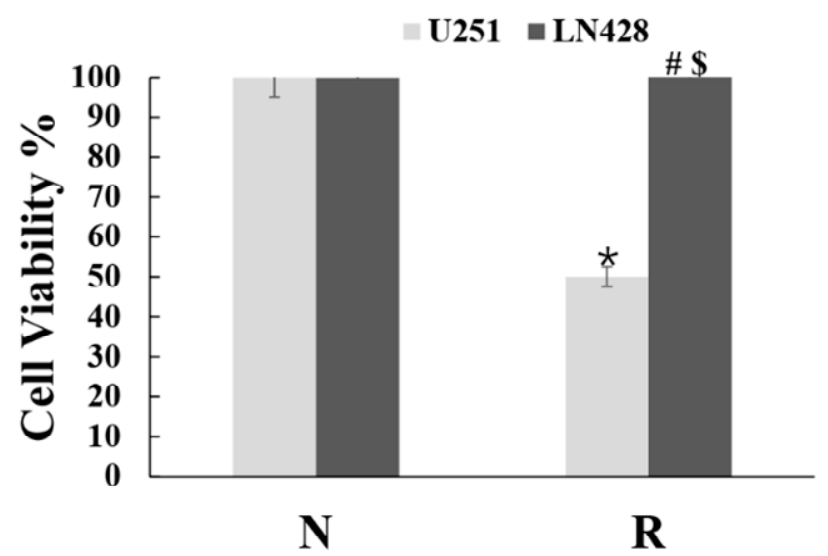

Figure 1. Distinct response of U251 and LN428 to resveratrol. (A) Hematoxylin and eosin morphological staining performed on U251 and LN428 cells without (N) or with treatment of $100 \mu$ M resveratrol (R) for $48 \mathrm{~h}(\times 100)$. Resveratrol causes growth arrest and apoptosis of U251 but not LN428 cells. (B) Evaluation of the cell viability of U251 and LN428 cells to resveratrol at $100 \mu \mathrm{M}$ for $48 \mathrm{~h}$ by MTT assay, U251/N vs. $\mathrm{U} 251 / \mathrm{R},{ }^{*}, p=0.4 \times 10^{-4}, \mathrm{LN} 428 / \mathrm{N}$ vs. LN428/R; $\#, p=0.302 ; \mathrm{LN} 428 / \mathrm{R}$ vs. U251/R, $\$, p=3 \times 10^{-4}$.

\subsection{Prepared Exosomes from U251 and LN428 Cells without and with Drug Treatment}

Hoechst DNA staining assay was used to detect mycoplasma infection and both U251 and LN428 cell lines are out of contamination. The exosomes were purified from supernatant of normally cultured U251 or LN428 cells as U251/or LN428/N/Exo, DMSO-treated as DMSO/Exo and resveratrol-treated as Res/Exo, respectively. Transmission electron microscopy (TEM) showed the presence of $30 \mathrm{~nm}$ to $200 \mathrm{~nm}$ membrane bounded vesicles (Figure 2A). In concordance, NTA revealed the exosome size distribution is from $30 \mathrm{~nm}-200 \mathrm{~nm}$ (Figure 2B,C). NTA-based exosome quantification showed that resveratrol promoted exosome release especially for both U215 and LN428 cells in the extents of 415.9\% and $12.1 \%$, respectively. Western blot analysis revealed that the exosome typical protein CD63 was enriched in exosome samples, while $\beta$-actin is undetectable (Figure 2D).

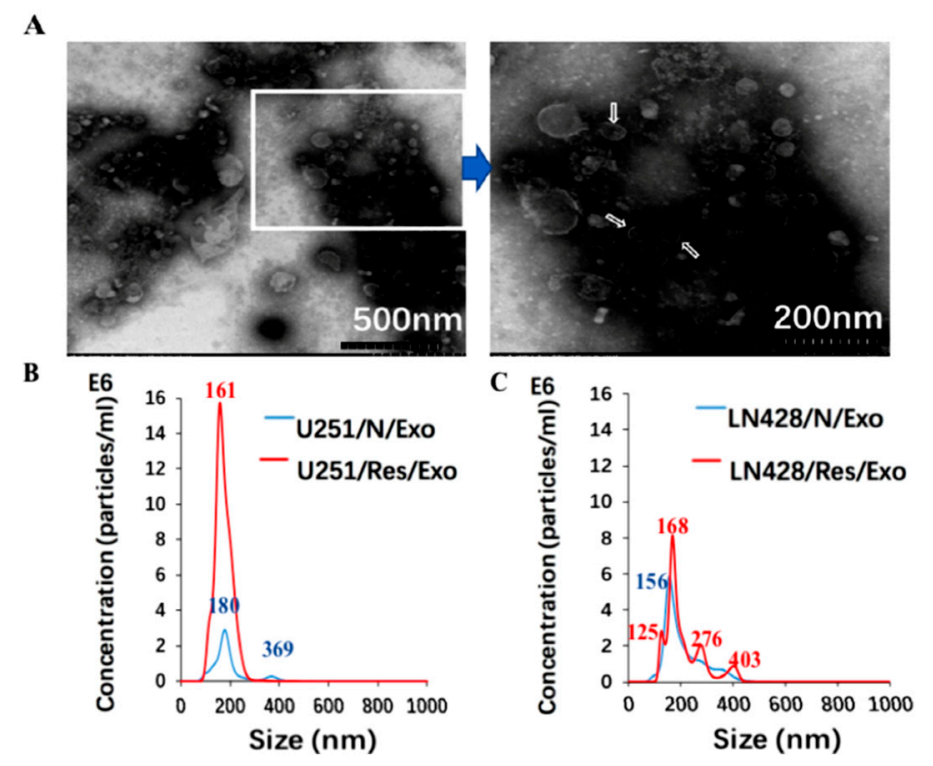

Figure 2. Cont. 
D

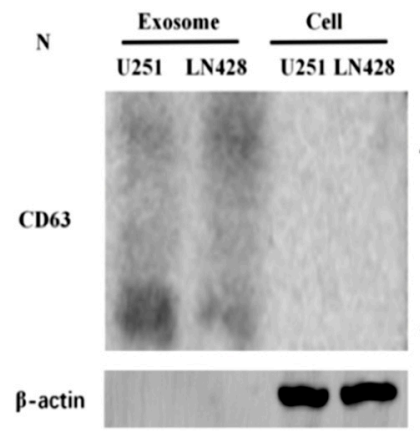

R $\frac{\text { Exosome }}{\text { U251 LN428 }} \frac{\text { Cell }}{\text { U251 LN428 }}$

4IKD

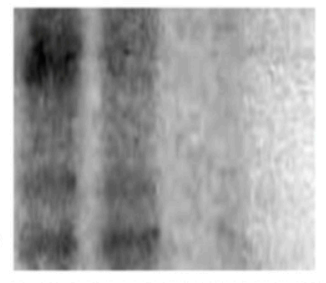

3KD

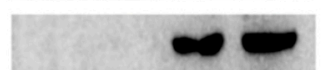

Figure 2. Identification of glioblastoma cell derived exosomes (Exo) purified from the supernatants by electron microscopy (A) and nanoparticle tracking analysis $(\mathbf{B}, \mathbf{C})$. In (A), the image inside the box is shown in higher magnification and the exosomes are indicated by the arrows. In (B,C), blue and red numbers indicate size of main peaks. Bar chart showing the average percentage of nanoparticles within 20-300 nm size and particle number/mL in vitro exosome preparation. Concentration and size distribution of exosomes derived from (B). Normal U251(U251/N) and treated U251 with resveratrol (U251/Res); (C). normal LN428 (LN428/N) and treating LN428 with resveratrol(LN428/Res) were measured by nanoparticle tracking analysis (NTA). Exosome concentration showed a peak at $180 \mathrm{~nm}$ (U251/N/Exo), $161 \mathrm{~nm}$ (U251/Res/Exo), $156 \mathrm{~nm}$ (LN428/N/Exo) and $125 \mathrm{~nm}, 168 \mathrm{~nm}$ (LN428/Res/Exo). (D). Western blot for the exosome-related proteins CD63 in U251/N/Exo, LN428/N/Exo, U251/Res/Exo and LN428/Res/Exo. The protein samples checked are positive in CD63 and negative in $\beta$-actin.

\subsection{U251/N/Exo but Not U251/Res/Exo Reversed Resveratrol Resistance of LN428 Cells}

Resveratrol-treated LN428 cells pre-incubated with U251/N/Exo showed significant growth suppression in comparison with their normally cultured and resveratrol-treated counterparts (Figure 3A). Exosomes from Res-treated U251 cells (U251/Res/Exo) failed to alter resveratrol resistance of LN428 (Figure 3A). The results of the MTT assay revealed a reduction of proliferation rates of $\mathrm{U} 251 / \mathrm{N} /$ Exo- $(\mathrm{OD}=0.624 \pm 0.027)$ rather than U251/Res/Exo- (OD $=0.703 \pm 0.047, \#, p=0.043)$ or phosphate buffered saline (PBS)-pre-incubated LN428 (OD $=0.743 \pm 0.040, *, p=0.011$ ) after being treated by resveratrol (Figure 3B). The resveratrol sensitive properties of $\mathrm{U} 251(\mathrm{OD}=0.310 \pm 0.020)$ remained unchanged, irrespective to LN428/N/Exo (0.0.295 $\pm 0.020, p=0.145)$ or LN428/Res/Exo $(0.334 \pm 0.036, p=0.173)$ pre-incubation (Figure $3 \mathrm{C}, \mathrm{D})$. 
A

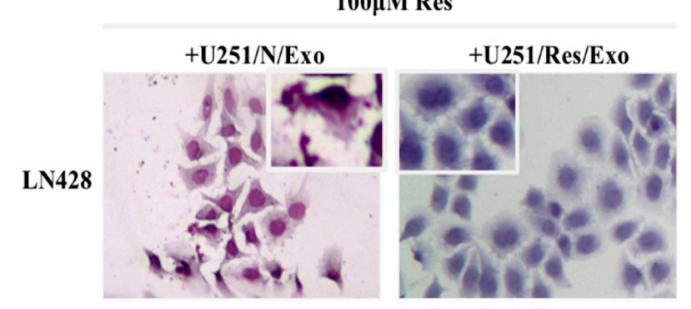

B

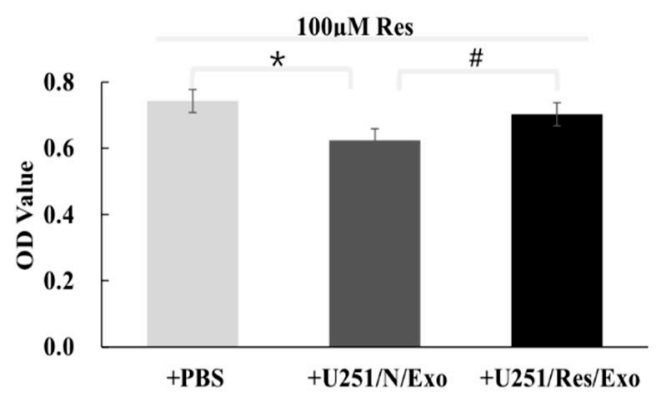

C

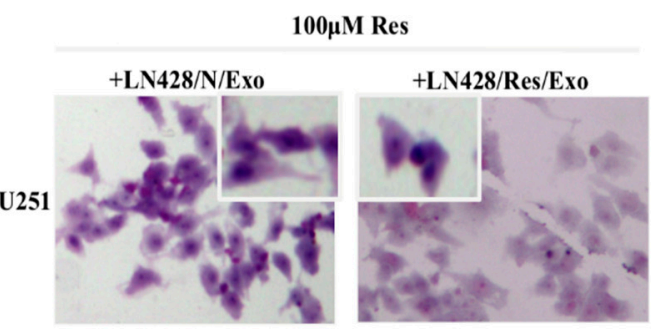

D

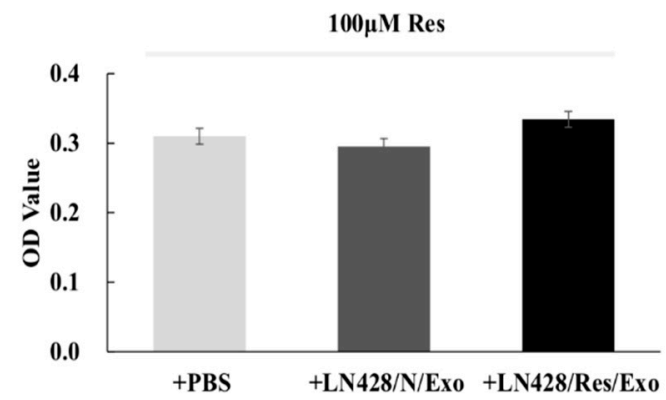

Figure 3. Impacts of exosomes from different origins. Hematoxylin and eosin staining and MTT assay were performed on the cell-bearing coverslips to assess resveratrol sensitivities of LN428 and U251 cells incubated with the exosomes derived from U251 and LN428 without and with resveratrol treatment. Morphology (A) and inhibition ratio (B) of LN428 cells treated by resveratrol and U251/N/Exo or U251/Res/Exo combination. The insets in (A) show the cells with higher magnification $(\times 200)$. *, $p=0.011 ; \#, p=0.043$. Morphology (C) and inhibition ratio (D) of U251 cells treated by resveratrol and LN428/N/Exo or LN428/Res/Exo combination. The insets in (C) show the cells with higher magnification $(\times 200)$. Resveratrol exerts similar growth suppression effects on the three groups $(p>0.05)$.

\subsection{Distinct Protein Compositions of U251- and LN428-Derived Exosomes}

The liquid chromatography-mass spectrometry (LC-MS/MS) raw data were searched against the human database. The representative proteins with significant changes ( $>1.3$ folds) between the U251 and LN428 cells without (N/Exo) and with resveratrol treatment (Res/Exo) are shown in Table 1. A total of 123 types of protein were identified in U25 and 216 in LN428 exosomes, respectively. The detailed protein database of each group is shown in the following diagram (Figure 4A-C). U251/N/Exo have higher Keratin (KRT including KRT18, KRT19) and H2A histone family member X (H2AX including H2AFX, HIST1H2AD) levels and lower Ras-related protein 1 (Rap1 including Rap1B, Rap1A), polymeric filaments form actin (F-actin including ACTB, ACTA2) levels, and guanine nucleotide binding protein (G protein including GNAS, GNAI). In contrast, the proteomic pattern of LN428/N/Exo is distinct to that of U251/N/Exo by showing lower KRT, H2AX and higher Rap1 and F-actin. The proteomic patterns of U251 and LN428 cells are altered by resveratrol in terms of KRT, H2AX, Rap1, F-actin and G protein being conversed. 
Table 1. Representative proteins in exosomes and their quantitative changes by resveratrol in U251 and LN428 cells.

\begin{tabular}{|c|c|c|c|c|c|c|c|c|}
\hline \multirow{2}{*}{ Uniprot Accession } & \multirow{2}{*}{ Protein } & \multicolumn{6}{|c|}{$\log _{2} R *$} & \multirow{2}{*}{ Biological Function } \\
\hline & & U251N/U251R & LN428N/LN428R & U251N/LN428N & U251R/LN428R & U251N/LN428R & U251R/LN428N & \\
\hline \multicolumn{9}{|c|}{ Pro-Differentiation } \\
\hline P05783 & KRT18 & $\uparrow \uparrow \uparrow *(2.74)$ & $\downarrow \downarrow(-1.23)$ & $\uparrow \uparrow(1.55)$ & $\downarrow \downarrow \downarrow *(-2.43)$ & $\uparrow(0.31)$ & $\downarrow \downarrow(-1.20)$ & Promotes differentiation [17] \\
\hline \multicolumn{9}{|c|}{ Tumor-Suppressor } \\
\hline P16104 & $\mathrm{H} 2 \mathrm{AX}$ & $\uparrow \uparrow(1.76)$ & $\downarrow(-0.44)$ & $\uparrow \uparrow(1.27)$ & $\downarrow \downarrow(-1.58)$ & $\uparrow(0.18)$ & $\downarrow(-0.48)$ & $\begin{array}{c}\text { Promotes apoptosis and } \\
\text { necroptosis }[18,19] \#\end{array}$ \\
\hline P02788 & LTF & $\uparrow \uparrow \uparrow *(2.84)$ & ND & ND & ND & ND & ND & Increases TMZ sensitivity [20] \# \\
\hline P01024 & $\mathrm{C} 3$ & ND & $\uparrow \uparrow \uparrow *(2.79)$ & ND & ND & ND & ND & $\begin{array}{c}\text { Increases TMZ and } \\
\text { photodynamic therapy } \\
\text { sensitivity [21]\# }\end{array}$ \\
\hline \multicolumn{9}{|c|}{ Tumor-Promoting } \\
\hline P61224 & RAP1B & $\downarrow(-0.94)$ & $\uparrow \uparrow(1.75)$ & $\downarrow \downarrow(-1.17)$ & $\uparrow \uparrow(1.51)$ & $\uparrow(0.58)$ & $\downarrow(-0.23)$ & $\begin{array}{l}\text { Promotes proliferation and } \\
\text { inhibits apoptosis [22] }\end{array}$ \\
\hline meP60709 & ACTB & $\downarrow \downarrow \downarrow *(-2.15)$ & $\uparrow(0.74)$ & $\downarrow \downarrow(-1.92)$ & $\uparrow(0.93)$ & $\downarrow \downarrow(-1.62)$ & $\uparrow(0.63)$ & The same as the above [23] \\
\hline Q5JWF2 & GNAS & $\downarrow \downarrow(-1.10)$ & ND & ND & ND & ND & ND & The same as the above [24] \\
\hline P08754 & GNAI3 & $\downarrow \downarrow(-1.10)$ & ND & ND & ND & ND & ND & The same as the above [24] \\
\hline \multicolumn{9}{|c|}{ Apoptosis and Necroptosis Pathway } \\
\hline Q12931 & TRAP1 & ND & $\uparrow \uparrow(1.99)$ & ND & ND & ND & ND & Reduces TMZ sensitivity [25] \$ \\
\hline Q58FF8 & HSP90AB2P & ND & $\uparrow \uparrow(1.89)$ & ND & ND & ND & ND & Reduces TMZ sensitivity [26] \$ \\
\hline
\end{tabular}

${ }^{*}$, Abundance ratios of (A Exo/B Exo; ND = Not Detected; $\log _{2}$ Ratio $>2=\uparrow \uparrow \uparrow,>1=\uparrow \uparrow,>0=\uparrow,<0=\downarrow,<-1=\downarrow \downarrow,<-2=\downarrow \downarrow ; \#$, Drug sensitizing factor; $\$$, Drug resistant factor. 
A

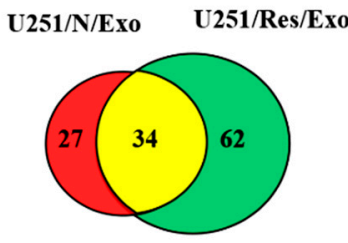

C

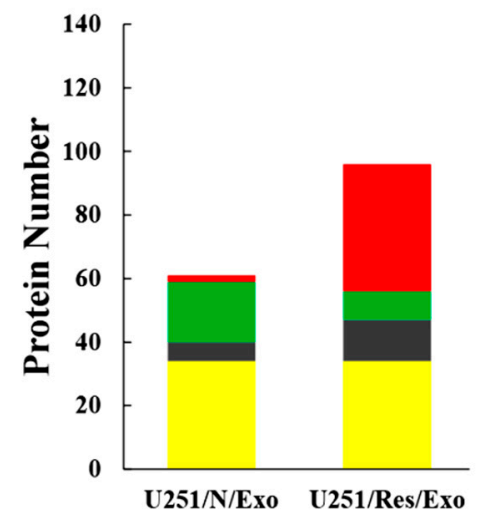

common unkonwn function $n$ tumor suppressor protein anco-protein
B LN428/N/Exo LN428/Res/Exo
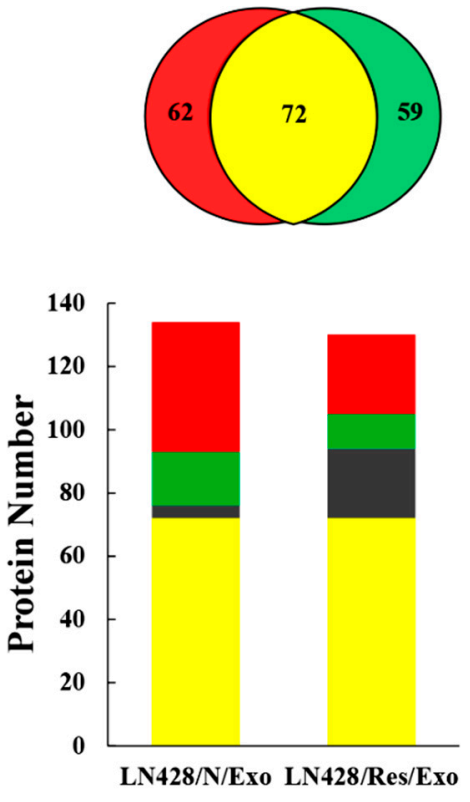

Figure 4. Proteomic analysis of U251 and LN428 cell-derived exosomes. (A,B) Venn diagram of liquid chromatography-mass spectrometry (LC-MS/MS)-identified proteins from U251 and LN428 cell-derived exosomes. (C) Subgroup numbers: Red, onco-proteins; Green, tumor suppressor proteins;

Grey, proteins with unknown function; Yellow, common proteins.

\subsection{Functional Classification of U251- and LN428-Derived Exosomic Proteins}

By the use of gene ontology enrichment (GO) analysis, the exosome-derived proteins were characterized according to their biological process, cellular component and molecular function (Figure 5A,B). The top cellular component GO annotation was 'extracellular exosomes' with 103 proteins out of 131 (U251/Exo) and 178 proteins out of 216 (LN428/Exo), confirming our exosome isolation efficiency. A Kyoto Encyclopedia of Genes and Genomes (KEGG) pathway analysis of these proteins were mapped (Figure 6A,B), the Rap1 signaling and necroptosis pathway $(p<0.001)$ are significant enriched in U251/N/Exo versus U251/Res/Exo, suggesting the regulatory role of exosomes within the drug sensitivity.

A

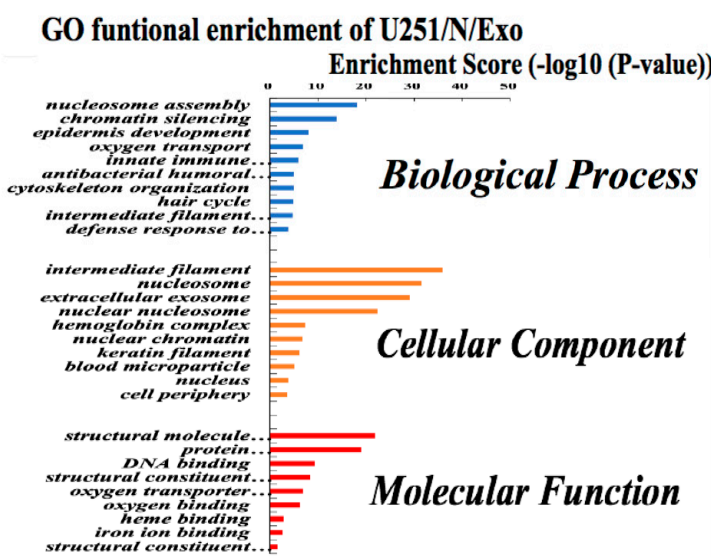

GO funtional enrichment of U251/Res/Exo

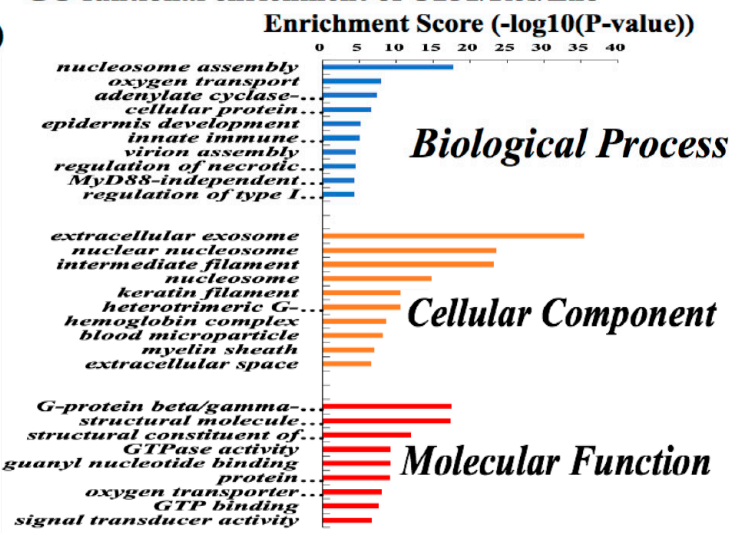

Figure 5. Cont. 


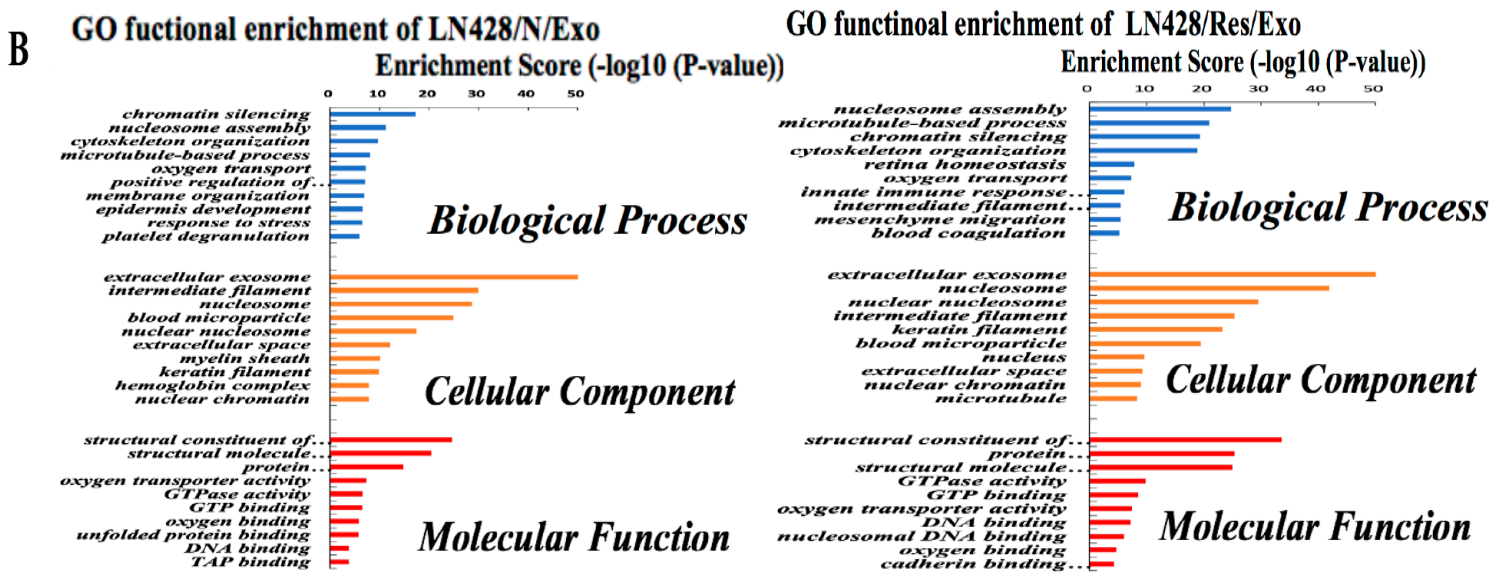

Figure 5. The identified proteins in U251- and LN428-derived exosomes were analyzed by gene ontology enrichment (GO) (A,B) in terms of biological process, cellular component, and molecular function annotation.

A

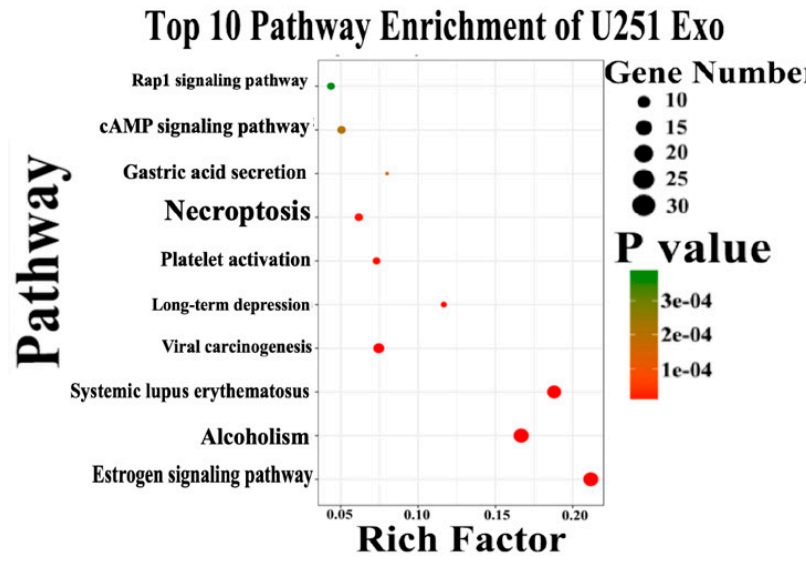

B

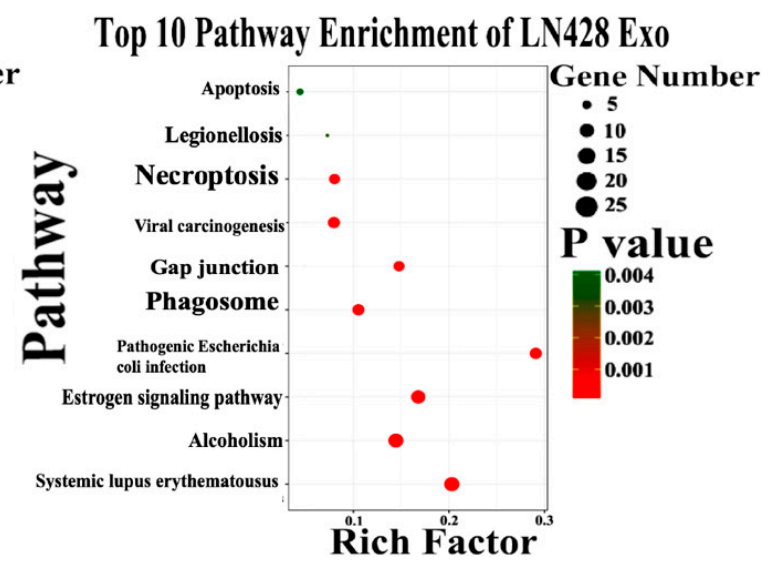

Figure 6. The top 10 pathway enrichment of differentially expressed exosome protein in U251 (A) and LN428 (B) cells were analyzed by Kyoto Encyclopedia of Genes and Genomes (KEGG) pathway.

\subsection{Differential Functional Enrichment in U251/N/Exo and U251/Res/Exo}

Comparative analysis reveals differential proteomic patterns between U251/N/Exo and U251/Res/Exos. In biological processes, U251/N/Exo tend to have higher expression on chromatin silencing and epidermis development, while U251/R/Exo contains more proteins involved in oxygen transport, G-protein coupled receptor signaling pathway and cellular protein metabolic process (Figure 5A). Molecular functional analysis shows that U251/N/Exo focus more on protein heterodimerization activity and DNA binding. U251/Res/Exo expression is higher than U251/N/Exo at certain precision molecular function, such as binding activity (G-protein complex binding and guanyl nucleotide binding) and GTPase activity (Figure 5A).

\subsection{Proteomic Similarities of LN428/N/Exo and LN428/Res/Exo}

Both LN428/N/Exo and LN428/Res/Exo share a number of proteins involved in the key biological processes and molecular function. The top 5 filtered biological processes were 'nucleosome assembly', 'microtubule-based process', 'chromatin silencing', 'cytoskeleton organization', and 'oxygen transport'. Moreover, the highest rich factors in molecular functional activities are the structural constituent of the cytoskeleton and enzymatic activity (structural molecule activity, protein 
heterodimerization activity, GTPase activity and oxygen transport activity). The detailed protein information is shown in Figure 5B.

\section{Discussion}

Severe side effects and frequent primary and secondary drug resistance are the main challenges of anti-glioblastoma chemotherapies [27]. For instance, advanced glioblastoma patients who develop resistance to temozolomide (TMZ) have limited opportunity for further treatment [28]. Consequently, there is an urgent clinical need to explore alternative lesser toxic approaches against glioblastomas. According to our previous studies [13], resveratrol would be such a candidate because this polyphenol compound is able to cross the blood-brain barrier via simple diffusion and exerts suppressive effects on rat RG2 formed orthotopic glioblastomas without affecting the normal function of the brain $[8,29]$. The therapeutic outcome of resveratrol is more promising when resveratrol is lumbar punctured after partial tumor removal [13]. In the case of human glioblastoma cell lines, resveratrol efficiently inhibits the growth of U251 cells that are partially sensitive to TMZ and finally acquire TMZ resistance after a long-term treatment [30]. On the other hand, LN428 cells harboring mutant p53, p14 and p16 deletions [31] are strongly resistant to both TMZ and resveratrol [32]. These results suggest that the treatment of human glioblastomas with resveratrol should be conducted in a personalized manner. In this context, it would be of translational value to investigate the underlying mechanism(s) resulting in differential responses of glioblastoma cells to resveratrol.

Many factors are known to be related with drug resistance, of which tumor-derived exosomes (TDEs) have been given increasing attention because they participate in many physiological as well as pathological processes [33]. The relevance of TDEs to drug resistance was also proposed because of their influence in telomerase activity of neuroblastoma cells [34] and reduced cisplatin sensitivity of ovarian cancer A2780 cells [35]. Given the above evidence, it would be possible that the exosomes secreted from LN428 cells may contain drug resistant elements that presumably reverse the resveratrol-sensitive properties of U251 cells; alternatively, the exosomes delivered from U251 cells may have little influence in the resveratrol resistance of LN428 cells. These issues are addressed in the current study by pre-incubating LN428 cells with U251-derived exosomes without (U251/N/Exo) or with resveratrol treatment (U251/Res/Exo) and vice versa. The results clearly reveal that U251/N/Exo but not U251/Res/Exo apparently enhance resveratrol sensitivity of LN428 cells. These findings, for the first time, demonstrate that drug resistance of cancer cells can be reversed by the use of exosomes from the drug-sensitive cancer cells. It is also possible that certain drug-sensitizing factors are present in the exosomes of drug sensitive cells like U251/N/Exo, which may be lost upon drug treatment. In other words, the exosomic contents are altered after resveratrol treatment, irrespective of the drug sensitivities of the treated cells. The investigation of proteomic patterns of the exosomes derived from U251 and LN428 cells before and after resveratrol treatment may further ascertain this point.

It has been found that the proteins in TDEs play active roles in drug resistance by transferring HSP, P53, PTEN and APC proteins [36]. So far, the comparative data concerning the exosomic protein contents in cancer cells with different drug sensitivities remain limited. Our proteomic analyses reveal that in comparison with the protein contents of U251/Res/Exo, the higher level of H2AX that sensitizes glioblastoma cells to apoptosis [37] and the lower levels of Rap1, F-actin and G proteins related with the enhanced drug sensitivity [38-40] and growth suppression of cancer cells [41] are found in U251/N/Exo. Phosphorylation of H2AX is an early sign of DNA damage induced by replication stalling [42]. It has been recognized that apoptosis requires H2AX for DNA ladder formation [43], and resveratrol can promote the apoptosis pathway via phosphorylating p38 and H2AX [18]. Given the evidence of the increased H2AX and reduced Rap1 signaling is associated with proteins in the exosomes derived from resveratrol-sensitive U251 cells, it is reasonable to consider that the resveratrol resistant properties of LN428 cells can be overcome after exposure to U251/N/Exo. Conversely, the predominant presence of Rap1, F-actin and G proteins instead of H2AX in U251/Res/Exo may explain the reason of the maintained resveratrol resistance of U251/Res/Exo pre-incubated LN428 cells. It has 
been known that an inflammatory microenvironment is associated with the development of GBM [44]. HSP70 as an inflammatory regulating protein can activate NF-kB-iNOS-COX2-TNF $\alpha$ inflammatory signaling [45] and suppression of NF- $\mathrm{kB}$ signaling accelerates resveratrol-treated medulloblastoma cells to apoptosis without differentiation [46]. We have found that the HSP70 level is 1.5 times higher in U251/Res/Exo than that in U251/N/Exo, suggesting the increased NF-KB activating factor(s) and, therefore, lesser resveratrol sensitivity of U251/Res/Exo-incubated cells. Consequently, the enriched drug-resistant elements in U251/Res/Exo can be regarded as a protective response to rersveratrol to keep growth and survival as has been found in neuroblastoma, breast cancer and ovarian cancer cells $[34,35,47]$.

It has been reported that drug tolerance can be induced by the exosomes of drug-resistant cell [48]. Because the drug resistant proteins are distinctly increased in U251/Res/Exo but the resveratrol-treated U251 cells are still subjected to cell crisis; the influence of exosomes secreted from resveratrol-resistant LN428 cells in resveratrol sensitivity of U251 cells is elucidated by incubating U251 cells with LN428/N/Exo and LN428/Res/Exo, respectively. The results reveal that those pre-incubated U251 cells remain sensitive to resveratrol as similar to those treated by resveratrol only $(p>0.05)$. Proteomic profiling of these two types of exosomes revealed that LN428/N/Exo and LN428/R/Exo share similar exosomic proteomic patterns in terms of the types of proteins detected and the abundance of onco-proteins such as HSP and F-actin that are in low levels in U251/N/Exo and increased in U251/Res/Exo as well $[49,50]$. HSP90A has been known as an exosome marker and a favorable factor for glioblastoma cell migration [51]. These results suggest that, unlike U251, resveratrol-resistant LN428 cells produce sufficient tolerance-related exosomic proteins even under normal conditions, by which they communicate drug resistant signals with each other [52]. Interestingly, neither LN428/N/Exo nor LN428/R/Exo lead U251 cells to resveratrol tolerance. Given this evidence and according to the multiple targeting feature of resveratrol, it is reasonable to consider that additional molecular events are caused by resveratrol in its sensitive cells, which would be more lethal to the treated cells such as the inactivated STAT3 signaling [53], increased oxidative stress [54] and activation of caspase-mediated apoptosis cascade [55].

In conclusion, the exosomic proteomic patterns of resveratrol-sensitive glioblastoma U251 and resveratrol-resistant LN428 cells are profiled before and after resveratrol treatment. The influences of those exosomes in resveratrol sensitivities are investigated by pre-incubating U251-derived exosomes (U251/N/Exo or U251/R/Exo) with LN428 and pre-incubating LN428-derived exosomes with (LN428/N/Exo or LN428/Res/Exo), respectively. The results clearly demonstrate that U251/N/Exo contains the higher levels of drug-sensitizing proteins and is able to reverse the resveratrol resistance of LN428 cells. U251/Res/Exo shows altered protein composition in terms of increased drug-resistant and reduced drug-sensitizing elements and, therefore, loss of the ability to reverse resveratrol resistance of LN428 cells. Although LN428/N/Exo and LN428/Res/Exo share similar exosomic proteomic patterns and are rich in onco-proteins, both of them fail to rescue U251 cells from resveratrol caused cell crisis. Our results thus suggest (1) that the exosomes from drug sensitive cells contain the proteins for a favorable therapeutic outcome; (2) that resveratrol can increase exosomic drug-resistant protein levels of the treated cells irrespective of their drug sensitivities; and (3) beyond exosomes, the presence or absence of more critical alterations determines the fate of resveratrol-treated glioblastoma cells.

\section{Materials and Methods}

\subsection{Glioblastoma Multiform (GBM) Cell Lines and Culture}

Human glioblastoma U251 cell line was obtained from the Cell Culture Facility, Chinese Academy of Sciences Cell Bank, Shanghai and LN428 cell line is generously provided by Professor Nicolas de Tribolet, Department of Neurosurgery, Central Hospital University of Laussane, Switzerland. The cells were routinely screened by Mycoplasma Stain Assay Kit (Beyotime Institute of Biotechnology, Beijing, China), and observed by fluorescence microscopy (Axio Imager 2; Carl Zeiss, Cambridge, UK). 
Cells were cultured in Dulbecco's modified Eagle medium with L-glutamine (DMEM; Gibco; Thermo Fisher Scientific, Waltham, MA, USA), supplemented with 10\% exosome-depleted fetal bovine serum (FBS) (ExoPerfectTM Exo-free FBS; Suer, Shanghai, China). An amount of $5 \times 10^{4} / \mathrm{mL}$ cells were plated onto culture dishes (Corning, NY, USA) at $37^{\circ} \mathrm{C}$ and $5 \% \mathrm{CO}_{2}$ for $48 \mathrm{~h}$ before the experiments were performed. For haematoxylin and eosin $(\mathrm{H} / \mathrm{E})$, dozens of cell-bearing coverslips were prepared under the same experimental conditions using coverslip-preparation dishes (Jet Biofile Tech. Inc., Guangzhou, China)

\subsection{Resveratrol Treatment and Cell Response}

Resveratrol (Sigma Chem CO., St. Louis, MO, USA) was dissolved in dimethylsulfoxide (DMSO; Sigma Chem CO., St. Louis, MO, USA) to a stock concentration of $100 \mathrm{mM}$ which was diluted with culture medium to the working concentration of $100 \mu \mathrm{M}$ for cell treatment. The two GBM cell lines were treated by $100 \mu \mathrm{M}$ resveratrol for $48 \mathrm{~h}$. The cells cultured routinely were used as normal control, and the cells cultured in the medium containing $0.1 \%$ DMSO as background control. Each of the experiments was set in triplicate, and the experiments were repeated at least three times to establish confidential conclusions.

\subsection{Evaluation of Cell Proliferation and Death}

To elucidate the cellular response of U251 and LN428 cells to resveratrol, H/E morphological staining, and 3-[4,5-Dimethylthiazol-2-yl]-2,5-diphenyl-tetrazolium bromide (MTT) cell proliferation assay were performed on cell-bearing coverslips without or with the drug treatment by the methods described elsewhere [14]. Cells treated with 0.1\% DMSO were used as background controls. The normally cultured cells were used as a negative control. Digital pathology scanner (Aperio CS2, Leica Biosystems, Nussloch, German) was used to observe and photograph the cells on coverslips.

\subsection{Sample Preparation and Exosome Isolation}

Exosomes were purified from supernatants from U251 (Ln428)/DMEM, U251 (LN428)/DMSO and U251 (LN428)/Res cultured in DMEM with 10\% exosome-depleted FBS. The exosomes were named as N/Exo, DMSO/Exo and Res/Exo for concisely. Briefly, supernatants were purified by differential ultracentrifugation $(300 \times g 10 \mathrm{~min}, 2000 \times \mathrm{g} 20 \mathrm{~min}, 16,500 \times g 20 \mathrm{~min}, 100,000 \times g 2 \mathrm{~h}$ at $4{ }^{\circ} \mathrm{C}$ ) on a Biosafe optima XPN-100 (Beckman Coulter, Brea, CA, USA). These rough exosomes were washed in PBS-0.22 $\mu \mathrm{m}$ syringe filter (Merck Millipore, Brulington, MA, USA), and re-centrifuge $100,000 \times g$ for another $2 \mathrm{~h}$ at $4{ }^{\circ} \mathrm{C}$. The final pellets contents the purified exosomes were resuspended in $100 \mu \mathrm{L}$ PBS and stored at $-80^{\circ} \mathrm{C}$.

\subsection{Transmission Electron Microscopy-Based Exosome Identification}

$5 \mu \mathrm{L}$ exosome samples of the experimental groups were fixed with $1 \%$ glutaraldehyde in PBS, and a $5 \mu \mathrm{L}$ drop of each sample was placed on a carbon-containing grid and incubated for $20 \mathrm{~min}$ at room temperature for electron microscopy; $5 \mu \mathrm{L}$ of $3 \%$ phosphotungstic acid $(\mathrm{PH}=7)$ was used to stain each sample for $5 \mathrm{~min}$, followed by observation under a transmission electron microscope (H-7650; Hitatchi high-technologies, Tokyo, Japan) at a voltage of $80 \mathrm{kV}$.

\subsection{Nanoparticle Tracking Analysis (NTA)-Based Exosome Quantification}

Nanoparticle tracking analysis (NTA) was employed to check the prepared exosome samples. Briefly, exosomes re-suspended in $50 \mu \mathrm{L}$ PBS were further diluted to 300-fold to achieve between 20 and 100 objects per frame and detected by NanoSight NS-300 (Malvern Panalytical, Malvern, UK). Each sample was measured in triplicate through the camera with an acquisition time of $30 \mathrm{~s}$ and the detection threshold was setting at 3. At least 200 completed were analyzed in each video. NTA 2.3 software was used to capture and analyze the result. 


\subsection{Protein Preparation and Western Blotting}

Total exosomic and cellular protein was extracted using RIPA lysis buffer (Beyotime Institute of Biotechnology, Beijing, China). The protein concentrations of cell and exosome lysates were determined using BCA protein assay kit (Beyotime Institute of Biotechnology, Beijing, China). For Western blot analyses, the cellular and exosomic proteins $(10 \mu \mathrm{g} /$ well) were separated by electrophoresis in $10 \%$ sodium dodecylsulfate-polyacrylamide gel electrophoresis, transferred to polyvinylidene difluoride membrane (Amersham, Buckinghamshire, UK). The membrane was blocked with 5\% skimmed milk in TBS-T (10 mM TrisCl, pH 8.0, $150 \mathrm{mM} \mathrm{NaCl}, 0.5 \%$ Tween 20$)$ at $4{ }^{\circ} \mathrm{C}$ overnight, rinsed three times (10 $\mathrm{min} /$ time) with TBS-T, followed by $3 \mathrm{~h}$ incubation at room temperature with a mouse anti-human CD63 antibody (1:500; Santa Cruz Biotechnology, Dallas, TX, USA) or mouse anti-human $\beta$-actin antibody (1:10,000; Proteintech Group, Chicago, IL, USA), followed by $1 \mathrm{~h}$ incubation with HRP-conjugated rabbit anti-mouse IgG (Zymed Lab, San Francisco, CA, USA). The bound antibody was detected using Amersham Imager 600 series imagers (GE Healthcare, Chicago, IL, USA).

\subsection{Exosome Pre-Incubation and Resveratrol Treatment}

LN428 cells were incubated with the $20 \mu \mathrm{g} / \mathrm{mL}$ exosomes derived from U251 cells without or with $48 \mathrm{~h} 100 \mu \mathrm{M}$ resveratrol treatment for $48 \mathrm{~h}$ by putting the LN428 coverslips to the 12-well plates, and the cells seeded in 96-well plates were treated in the same manner for MTT assay. U251 derived $\mathrm{N} /$ Exo, DMSO/Exo, Res/Exo $(20 \mu \mathrm{g} / \mathrm{mL}$ ) or PBS (vehicle), were respectively used to incubate with LN428 cells for $48 \mathrm{~h}$, followed by $100 \mu \mathrm{M}$ resveratrol or $0.1 \%$ DMSO treatment for another $48 \mathrm{~h}$. The collected cell-bearing coverslips were subjected to HE staining; the cells in 96-well plates to MTT assay. U251 cells were treated in the same manners, using LN428 derived N/Exo, DMSO/Exo, Res/Exo $(20 \mu \mathrm{g} / \mathrm{mL})$ or PBS (vehicle), respectively.

\subsection{Trypsin Digestion and Desalting}

Tryptic digestion on exosome for each group was performed as described previously with modifications [56]; $50 \mu \mathrm{g}$ exosome samples (detected by BCA) were precipitated by ice-cold acetone (acetone/sample 4:1) and place at $-20{ }^{\circ} \mathrm{C}$ for overnight. Reducing was then undertaken in $500 \mu \mathrm{M}$ of DTT for $1.5 \mathrm{~h}$ and protecting by incubation in $6.5 \mu \mathrm{L} 50 \mathrm{mM}$ IAA in dark for $40 \mathrm{~min}$ at room temperature. Tryptic digestion was done for $24 \mathrm{~h}$ at $37^{\circ} \mathrm{C}$ to digest exosomal proteins of each experimental groups. Peptide desalting was performed (Pierce C18 Tips; Thermo Fisher Scientific, Waltham, MA, USA). Finally, the samples were eluted sequentially with $0.1 \%$ acetic acid in a $80 \% \mathrm{ACN}$ and dispense into a Eppendorf tube. The combined eluate was concentrated in a Vacuum Concentrator (Labconco, Kansas City, MO, USA), then resuspended by $30 \mu \mathrm{L} 0.1 \%$ formic acid solution and injected into an autosampler vial for further LC-MS test.

\subsection{Liquid Chromatography-Mass Spectrometry (LC-MS/MS) Analysis}

Digested exosome peptides were analyzed by reversed-phase LC on an Easy-nLc 1000 system directly accompanied with a Q Exactive Plus Orbitrap mass spectrometer (Thermo Fisher Scientific, USA) by a nanoelectrospray source (Thermo Fisher Scientific, USA). Using $20 \mathrm{~cm}$ length and $75 \mu \mathrm{m}$ inner diameter to pack in house with ReproSil-Pur 130C18-AQ $3 \mu \mathrm{m}$ particles (Dr. Maisch HPLC $\mathrm{GmbH}$, Germany). The peptide mixtures were separated using 75 min linear gradients and a two-buffer system, including buffer A ( $0.1 \% \mathrm{FA})$ and buffer B (ACN $/ 0.1 \% \mathrm{FA})$. The flow rate was set to $300 \mathrm{~nL} / \mathrm{min}$. Peptides effusion from the column were sprayed into the mass spectrometer with a spray voltage of $2.3 \mathrm{kV}$ with a $300{ }^{\circ} \mathrm{C}$ capillary. The mass spectrometer was working in a data-dependent mode, requiring a survey scan at 70,000 resolution with a maximum injection time of $50 \mathrm{~ms}$ and an automatic gain control (AGC) target of $3 \times 10^{6}$ ions. Furthermore, the scanning range is from 300 to $2000 \mathrm{~m} / z$. 


\subsection{Database Search and Bioinformatic Analyses}

Raw MS data were processed using Proteome Discoverer (Version 1.4.0.288, Thermo Fisher Scientific, Bremen, Germany) with the search engine SEQUEST HT. MS/MS spectra were searched against the UniprotKB human database (downloaded on, 2018). The peptide mass, fragment mass tolerance and maximum missed cleavage sties were respectively set as $10 \mathrm{ppm}, 20 \mathrm{mDa}$ and 2 sites. Moreover, a $1 \%$ false discovery rate was used to filter the identification peptides. As for quantitative analysis of MS results, we used a label-free analysis to calculate the quantitative changes of the identified proteins among different groups. To identify the most significantly differentially expressed protein, we analyzed the data through GO and KEGG pathway analyses. Proteins with expression fold change $>1.3$ and Student's $t$-test, $p<0.05$ were filtered as differentially expressed proteins between exosomes isolated from different groups.

\subsection{Statistical Analysis}

The results of cell counting and MTT assay were evaluated with the independent-samples $t$-test and analysis of variance (ANOVA). Data were presented as mean \pm standard deviation (SD) of separate experiments $(\mathrm{n} \geq 10)$. When required, $p$-values are stated in the figure legends $\left({ }^{*} p<0.05 ;{ }^{* *} p<0.01\right)$.

Author Contributions: J.L. and H.L., undertook the experimental design, data analyses, and manuscript writing; J.-H.N., M.-L.W. performed the experiments; X.-M.L., L.X. assisted in exosome isolation; all authors read and approved the final manuscript.

Funding: This work was supported by grants from the National Natural Science Foundation of China (Nos. 81450016, 81272786, 81071971, 81072063 and 30971038), a Special Research Fund for Emerging Subjects from South China University of Technology.

Acknowledgments: The authors thank Xue Song in the Department of Cell Biology, College of Basic Medical Sciences, Dalian Medical University for technical assistance.

Conflicts of Interest: The authors have no conflicts of interest to declare.

\section{References}

1. Ostrom, Q.T.; Gittleman, H.; Liao, P.; Vecchione-Koval, T.; Wolinsky, Y.; Kruchko, C.; Barnholtz-Sloan, J.S. CBTRUS statistical report: Primary brain and other central nervous system tumors diagnosed in the United States in 2010-2014. Neuro Oncol. 2017, 19, v1-v88. [CrossRef] [PubMed]

2. Stupp, R.; Mason, W.P.; van den Bent, M.J.; Weller, M.; Fisher, B.; Taphoorn, M.J.; Belanger, K.; Brandes, A.A.; Marosi, C.; Bogdahn, U.; et al. Radiotherapy plus concomitant and adjuvant temozolomide for glioblastoma. N. Engl. J. Med. 2005, 352, 987-996. [CrossRef] [PubMed]

3. Weller, M.; van den Bent, M.; Hopkins, K.; Tonn, J.C.; Stupp, R.; Falini, A.; Cohen-Jonathan-Moyal, E.; Frappaz, D.; Henriksson, R.; Balana, C.; et al. EANO guideline for the diagnosis and treatment of anaplastic gliomas and glioblastoma. Lancet Oncol. 2014, 15, e395-e403. [CrossRef]

4. Stepanovic, A.; Nikitovic, M. Severe hematologic temozolomide-related toxicity and lifethreatening infections. J. BUON 2018, 23, 7-13. [PubMed]

5. Bae, S.H.; Park, M.J.; Lee, M.M.; Kim, T.M.; Lee, S.H.; Cho, S.Y.; Kim, Y.H.; Kim, Y.J.; Park, C.K.; Kim, C.Y. Toxicity profile of temozolomide in the treatment of 300 malignant glioma patients in Korea. J. Korean Med. Sci. 2014, 29, 980-984. [CrossRef] [PubMed]

6. Athar, M.; Back, J.H.; Kopelovich, L.; Bickers, D.R.; Kim, A.L. Multiple molecular targets of resveratrol: Anti-carcinogenic mechanisms. Arch. Biochem. Biophys. 2009, 486, 95-102. [CrossRef] [PubMed]

7. Wang, Q.; Xu, J.; Rottinghaus, G.E.; Simonyi, A.; Lubahn, D.; Sun, G.Y.; Sun, A.Y. Resveratrol protects against global cerebral ischemic injury in gerbils. Brain Res. 2002, 958, 439-447. [CrossRef]

8. Gambini, J.; Ingles, M.; Olaso, G.; Lopez-Grueso, R.; Bonet-Costa, V.; Gimeno-Mallench, L.; Mas-Bargues, C.; Abdelaziz, K.M.; Gomez-Cabrera, M.C.; Vina, J.; et al. Properties of resveratrol: In vitro and in vivo studies about metabolism, bioavailability, and biological effects in animal models and humans. Oxid. Med. Cell. Longev. 2015, 2015, 837042. [CrossRef] 
9. Boocock, D.J.; Faust, G.E.; Patel, K.R.; Schinas, A.M.; Brown, V.A.; Ducharme, M.P.; Booth, T.D.; Crowell, J.A.; Perloff, M.; Gescher, A.J.; et al. Phase I dose escalation pharmacokinetic study in healthy volunteers of resveratrol, a potential cancer chemopreventive agent. Cancer Epidemiol. Biomark. Prev. 2007, 16, 1246-1252. [CrossRef]

10. Juan, M.E.; Maijo, M.; Planas, J.M. Quantification of trans-resveratrol and its metabolites in rat plasma and tissues by HPLC. J. Pharm. Biomed. Anal. 2010, 51, 391-398. [CrossRef]

11. Pistollato, F.; Bremer-Hoffmann, S.; Basso, G.; Cano, S.S.; Elio, I.; Vergara, M.M.; Giampieri, F.; Battino, M. Targeting glioblastoma with the use of phytocompounds and nanoparticles. Target. Oncol. 2016, 11, 1-16. [CrossRef] [PubMed]

12. Xue, S.; Shu, X.-H.; Lin, S.; Jie, B.; Wang, L.-L.; Gu, J.-Y.; Shun, S.; Li, P.-N.; Wu, M.-L.; Qian, W.; et al. Lumbar puncture-administered resveratrol inhibits STAT3 activation, enhancing autophagy and apoptosis in orthotopic rat glioblastomas. Oncotarget 2016, 7, 75790-75799. [CrossRef] [PubMed]

13. Song, X.; Shu, X.H.; Wu, M.L.; Zheng, X.; Jia, B.; Kong, Q.Y.; Liu, J.; Li, H. Postoperative resveratrol administration improves prognosis of rat orthotopic glioblastomas. BMC Cancer 2018, 18, 871. [CrossRef] [PubMed]

14. Sun, Z.; Li, H.; Shu, X.H.; Shi, H.; Chen, X.Y.; Kong, Q.Y.; Wu, M.L.; Liu, J. Distinct sulfonation activities in resveratrol-sensitive and resveratrol-insensitive human glioblastoma cells. FEBS J. 2012, 279, 2381-2392. [CrossRef] [PubMed]

15. Li, H.; Jia, Z.; Li, A.; Jenkins, G.; Yang, X.; Hu, J.; Guo, W. Resveratrol repressed viability of U251 cells by miR-21 inhibiting of NF-kappaB pathway. Mol. Cell. Biochem. 2013, 382, 137-143. [CrossRef]

16. Yang, J.K.; Yang, J.P.; Tong, J.; Jing, S.Y.; Fan, B.; Wang, F.; Sun, G.Z.; Jiao, B.H. Exosomal miR-221 targets DNM3 to induce tumor progression and temozolomide resistance in glioma. J. Neuro-Oncol. 2017, 131, 255-265. [CrossRef] [PubMed]

17. Fevre-Montange, M.; Champier, J.; Szathmari, A.; Wierinckx, A.; Mottolese, C.; Guyotat, J.; Figarella-Branger, D.; Jouvet, A.; Lachuer, J. Microarray analysis reveals differential gene expression patterns in tumors of the pineal region. J. Neuropathol. Exp. Neurol. 2006, 65, 675-684. [CrossRef] [PubMed]

18. Wu, X.P.; Xiong, M.; Xu, C.S.; Duan, L.N.; Dong, Y.Q.; Luo, Y.; Niu, T.H.; Lu, C.R. Resveratrol induces apoptosis of human chronic myelogenous leukemia cells in vitro through p38 and JNK-regulated H2AX phosphorylation. Acta Pharmacol. Sin. 2015, 36, 353-361. [CrossRef]

19. Pasupuleti, N.; Leon, L.; Carraway, K.L., III; Gorin, F. 5-Benzylglycinyl-amiloride kills proliferating and nonproliferating malignant glioma cells through caspase-independent necroptosis mediated by apoptosis-inducing factor. J. Pharmacol. Exp. Ther. 2013, 344, 600-615. [CrossRef]

20. Arcella, A.; Oliva, M.A.; Staffieri, S.; Aalberti, S.; Grillea, G.; Madonna, M.; Bartolo, M.; Pavone, L.; Giangaspero, F.; Cantore, G.; et al. In vitro and in vivo effect of human lactoferrin on glioblastoma growth. J. Neurosurg. 2015, 123, 1026-1035. [CrossRef]

21. Li, F.; Cheng, Y.; Lu, J.; Hu, R.; Wan, Q.; Feng, H. Photodynamic therapy boosts anti-glioma immunity in mice: A dependence on the activities of T cells and complement C3. J. Cell. Biochem. 2011, 112, 3035-3043. [CrossRef] [PubMed]

22. Li, Z.; Xu, C.; Ding, B.; Gao, M.; Wei, X.; Ji, N. Long non-coding RNA MALAT1 promotes proliferation and suppresses apoptosis of glioma cells through derepressing Rap1B by sponging miR-101. J. Neuro-Oncol. 2017, 134, 19-28. [CrossRef] [PubMed]

23. Jovcevska, I.; Zupanec, N.; Urlep, Z.; Vranic, A.; Matos, B.; Stokin, C.L.; Muyldermans, S.; Myers, M.P.; Buzdin, A.A.; Petrov, I.; et al. Differentially expressed proteins in glioblastoma multiforme identified with a nanobody-based anti-proteome approach and confirmed by OncoFinder as possible tumor-class predictive biomarker candidates. Oncotarget 2017, 8, 44141-44158. [CrossRef] [PubMed]

24. Cherry, A.E.; Stella, N. G protein-coupled receptors as oncogenic signals in glioma: Emerging therapeutic avenues. Neuroscience 2014, 278, 222-236. [CrossRef] [PubMed]

25. Wu, J.; Liu, Y.; Cho, K.; Dong, X.; Teng, L.; Han, D.; Liu, H.; Chen, X.; Chen, X.; Hou, X.; et al. Downregulation of TRAP1 sensitizes glioblastoma cells to temozolomide chemotherapy through regulating metabolic reprogramming. Neuroreport 2016, 27, 136-144. [CrossRef] [PubMed]

26. Canella, A.; Welker, A.M.; Yoo, J.Y.; Xu, J.; Abas, F.S.; Kesanakurti, D.; Nagarajan, P.; Beattie, C.E.; Sulman, E.P.; Liu, J.; et al. Efficacy of onalespib, a long-acting second-generation HSP90 inhibitor, as a single agent and in combination with temozolomide against malignant gliomas. Clin. Cancer Res. 2017, 23, 6215-6226. [CrossRef] 
27. Westphal, M.; Heese, O.; Steinbach, J.P.; Schnell, O.; Schackert, G.; Mehdorn, M.; Schulz, D.; Simon, M.; Schlegel, U.; Senft, C.; et al. A randomised, open label phase III trial with nimotuzumab, an anti-epidermal growth factor receptor monoclonal antibody in the treatment of newly diagnosed adult glioblastoma. Eur. J. Cancer 2015, 51, 522-532. [CrossRef]

28. Rehman, A.A.; Elmore, K.B.; Mattei, T.A. The effects of alternating electric fields in glioblastoma: Current evidence on therapeutic mechanisms and clinical outcomes. Neurosurg. Focus 2015, 38, E14. [CrossRef]

29. Jiao, Y.; Li, H.; Liu, Y.; Guo, A.; Xu, X.; Qu, X.; Wang, S.; Zhao, J.; Li, Y.; Cao, Y. Resveratrol inhibits the invasion of glioblastoma-initiating cells via down-regulation of the PI3K/Akt/NF-kappaB signaling pathway. Nutrients 2015, 7, 4383-4402. [CrossRef]

30. Song, Z.; Pan, Y.; Ling, G.; Wang, S.; Huang, M.; Jiang, X.; Ke, Y. Escape of U251 glioma cells from temozolomide-induced senescence was modulated by CDK1/survivin signaling. Am. J. Transl. Res. 2017, 9, 2163-2180.

31. Ishii, N.; Maier, D.; Merlo, A.; Tada, M.; Sawamura, Y.; Diserens, A.C.; Van Meir, E.G. Frequent co-alterations of TP53, p16/CDKN2A, p14ARF, PTEN tumor suppressor genes in human glioma cell lines. Brain Pathol. 1999, 9, 469-479. [CrossRef] [PubMed]

32. Tang, J.B.; Svilar, D.; Trivedi, R.N.; Wang, X.H.; Goellner, E.M.; Moore, B.; Hamilton, R.L.; Banze, L.A.; Brown, A.R.; Sobol, R.W. N-methylpurine DNA glycosylase and DNA polymerase beta modulate BER inhibitor potentiation of glioma cells to temozolomide. Neuro Oncol. 2011, 13, 471-486. [CrossRef] [PubMed]

33. Shao, Y.; Shen, Y.; Chen, T.; Xu, F.; Chen, X.; Zheng, S. The functions and clinical applications of tumor-derived exosomes. Oncotarget 2016, 7, 60736-60751. [CrossRef] [PubMed]

34. Challagundla, K.B.; Wise, P.M.; Neviani, P.; Chava, H.; Murtadha, M.; Xu, T.; Kennedy, R.; Ivan, C.; Zhang, X.; Vannini, I.; et al. Exosome-mediated transfer of microRNAs within the tumor microenvironment and neuroblastoma resistance to chemotherapy. J. Natl. Cancer Inst. 2015, 107. [CrossRef] [PubMed]

35. Pink, R.C.; Samuel, P.; Massa, D.; Caley, D.P.; Brooks, S.A.; Carter, D.R. The passenger strand, miR-21-3p, plays a role in mediating cisplatin resistance in ovarian cancer cells. Gynecol. Oncol. 2015, 137, 143-151. [CrossRef] [PubMed]

36. Azmi, A.S.; Bao, B.; Sarkar, F.H. Exosomes in cancer development, metastasis, and drug resistance: A comprehensive review. Cancer Metastasis Rev. 2013, 32, 623-642. [CrossRef] [PubMed]

37. Liu, Y.; Parry, J.A.; Chin, A.; Duensing, S.; Duensing, A. Soluble histone H2AX is induced by DNA replication stress and sensitizes cells to undergo apoptosis. Mol. Cancer 2008, 7, 61. [CrossRef]

38. Xiao, L.; Lan, X.; Shi, X.; Zhao, K.; Wang, D.; Wang, X.; Li, F.; Huang, H.; Liu, J. Cytoplasmic RAP1 mediates cisplatin resistance of non-small cell lung cancer. Cell Death Dis. 2017, 8, e2803. [CrossRef]

39. Tiek, D.M.; Rone, J.D.; Graham, G.T.; Pannkuk, E.L.; Haddad, B.R.; Riggins, R.B. Alterations in cell motility, proliferation, and metabolism in novel models of acquired temozolomide resistant glioblastoma. Sci. Rep. 2018, 8, 7222. [CrossRef]

40. Woerner, B.M.; Luo, J.; Brown, K.R.; Jackson, E.; Dahiya, S.M.; Mischel, P.; Benovic, J.L.; Piwnica-Worms, D.; Rubin, J.B. Suppression of G-protein-coupled receptor kinase 3 expression is a feature of classical GBM that is required for maximal growth. Mol. Cancer Res. 2012, 10, 156-166. [CrossRef]

41. Zhang, Y.L.; Wang, R.C.; Cheng, K.; Ring, B.Z.; Su, L. Roles of Rap1 signaling in tumor cell migration and invasion. Cancer Biol. Med. 2017, 14, 90-99. [CrossRef]

42. Fragkos, M.; Jurvansuu, J.; Beard, P. H2AX is required for cell cycle arrest via the p53/p21 pathway. Mol. Cell. Biol. 2009, 29, 2828-2840. [CrossRef]

43. Lu, C.; Zhu, F.; Cho, Y.Y.; Tang, F.; Zykova, T.; Ma, W.Y.; Bode, A.M.; Dong, Z. Cell apoptosis: Requirement of H2AX in DNA ladder formation, but not for the activation of caspase-3. Mol. Cell 2006, 23, 121-132. [CrossRef] [PubMed]

44. Quail, D.F.; Joyce, J.A. The microenvironmental landscape of brain tumors. Cancer Cell 2017, 31, $326-341$. [CrossRef] [PubMed]

45. Yu, W.W.; Cao, S.N.; Zang, C.X.; Wang, L.; Yang, H.Y.; Bao, X.Q.; Zhang, D. Heat shock protein 70 suppresses neuroinflammation induced by alpha-synuclein in astrocytes. Mol. Cell. Neurosci. 2018, 86, 58-64. [CrossRef] [PubMed]

46. Wen, S.; Li, H.; Wu, M.L.; Fan, S.H.; Wang, Q.; Shu, X.H.; Kong, Q.Y.; Chen, X.Y.; Liu, J. Inhibition of NF-kappaB signaling commits resveratrol-treated medulloblastoma cells to apoptosis without neuronal differentiation. J. Neuro-Oncol. 2011, 104, 169-177. [CrossRef] 
47. O’Brien, K.; Lowry, M.C.; Corcoran, C.; Martinez, V.G.; Daly, M.; Rani, S.; Gallagher, W.M.; Radomski, M.W.; MacLeod, R.A.; O'Driscoll, L. miR-134 in extracellular vesicles reduces triple-negative breast cancer aggression and increases drug sensitivity. Oncotarget 2015, 6, 32774-32789. [CrossRef]

48. Qu, L.; Ding, J.; Chen, C.; Wu, Z.J.; Liu, B.; Gao, Y.; Chen, W.; Liu, F.; Sun, W.; Li, X.F.; et al. Exosome-transmitted lncARSR promotes sunitinib resistance in renal cancer by acting as a competing endogenous RNA. Cancer Cell 2016, 29, 653-668. [CrossRef]

49. Santos, T.G.; Martins, V.R.; Hajj, G.N.M. Unconventional secretion of heat shock proteins in cancer. Int. J. Mol. Sci. 2017, 18, 946. [CrossRef]

50. Akakura, N.; Hoogland, C.; Takada, Y.K.; Saegusa, J.; Ye, X.; Liu, F.T.; Cheung, A.T.; Takada, Y. The $\mathrm{COOH}$-terminal globular domain of fibrinogen gamma chain suppresses angiogenesis and tumor growth. Cancer Res. 2006, 66, 9691-9697. [CrossRef]

51. Thuringer, D.; Hammann, A.; Benikhlef, N.; Fourmaux, E.; Bouchot, A.; Wettstein, G.; Solary, E.; Garrido, C. Transactivation of the epidermal growth factor receptor by heat shock protein 90 via Toll-like receptor 4 contributes to the migration of glioblastoma cells. J. Biol. Chem. 2011, 286, 3418-3428. [CrossRef] [PubMed]

52. Zhang, C.; Ji, Q.; Yang, Y.; Li, Q.; Wang, Z. Exosome: Function and role in cancer metastasis and drug resistance. Technol. Cancer Res. Treat. 2018, 17. [CrossRef] [PubMed]

53. Yang, Y.P.; Chang, Y.L.; Huang, P.I.; Chiou, G.Y.; Tseng, L.M.; Chiou, S.H.; Chen, M.H.; Chen, M.T.; Shih, Y.H.; Chang, C.H.; et al. Resveratrol suppresses tumorigenicity and enhances radiosensitivity in primary glioblastoma tumor initiating cells by inhibiting the STAT3 axis. J. Cell. Physiol. 2012, 227, 976-993. [CrossRef] [PubMed]

54. Martins, L.A.; Coelho, B.P.; Behr, G.; Pettenuzzo, L.F.; Souza, I.C.; Moreira, J.C.; Borojevic, R.; Gottfried, C.; Guma, F.C. Resveratrol induces pro-oxidant effects and time-dependent resistance to cytotoxicity in activated hepatic stellate cells. Cell Biochem. Biophys. 2014, 68, 247-257. [CrossRef] [PubMed]

55. Jiang, H.; Zhang, L.; Kuo, J.; Kuo, K.; Gautam, S.C.; Groc, L.; Rodriguez, A.I.; Koubi, D.; Hunter, T.J.; Corcoran, G.B.; et al. Resveratrol-induced apoptotic death in human U251 glioma cells. Mol. Cancer Ther. 2005, 4, 554-561. [CrossRef] [PubMed]

56. Bilen, M.A.; Pan, T.; Lee, Y.C.; Lin, S.C.; Yu, G.; Pan, J.; Hawke, D.; Pan, B.F.; Vykoukal, J.; Gray, K.; et al. Proteomics profiling of exosomes from primary mouse osteoblasts under proliferation versus mineralization conditions and characterization of their uptake into prostate cancer cells. J. Proteome Res. 2017, 16, 2709-2728. [CrossRef] [PubMed]

(C) 2019 by the authors. Licensee MDPI, Basel, Switzerland. This article is an open access article distributed under the terms and conditions of the Creative Commons Attribution (CC BY) license (http:/ / creativecommons.org/licenses/by/4.0/). 